\title{
Opinion
}

\section{Science \& technology in a post-Covid-19 world}

\author{
JAIRAM RAMESH \\ MP and Chairman of Parliament's Standing Committee on Science \& Technology, Environment, \\ Forests \& Climate Change, New Delhi, India \\ (Email, jairam54@gmail.com)
}

Published online 17 December 2020

I

I am delighted to have this opportunity to speak, even if it be virtually, to the Indian Academy of Sciences that has had such a distinguished history. I know something about the Academy because of my life-long fascination with C.V. Raman but in recent times have got to know even more about it. This was because I was toying with the idea of writing a biography of E.K. Janaki Ammal, who was the Academy's very first woman member way back in 1935 just a year after the Academy's founding. As it turns out, a historian of science beat me to it and her biography of India's first woman botanist will soon be out.

I wish to begin by paying my respects and tribute to one of the past presidents of the Academy whose birth centenary was celebrated just a few weeks ago. Satish Dhawan is a legendary figure who gave shape and direction to our country's space programme. But for me it was Satish Dhawan - the humanist - who remains an inspiring figure. The progressive values he cherished and stood for, the democratic and liberal causes he championed and the profound respect he had for India's diversity and plurality are all very relevant today. I am glad to say that in recent months on two occasions that I can remember, many members of the Indian S\&T community have stood up and have had the courage of their social convictions. The flames of this courage have to be kept burning bright to continue to celebrate our plurality and diversity and uphold scientific reasoning and rationality and nurture scientific temper.

\section{II}

History is divided into two periods: Before the Common Era or BCE and Common Era or CE. But given our experience this year, BCE could well stand for Before Covid-19 Epidemic and CE for Covid-19 Epidemic. To say that 2020 has been cataclysmic is to state the obvious and actually to make an understatement. Our lives have been turned upside down. We may have an economic recovery of sorts but the trauma that each and every one of us has

Public Lecture delivered virtually at the 86th Annual Meeting of the Indian Academy of Sciences, 7 November 2020.

The views expressed in this opinion-article are solely those of the author, and not necessarily endorsed by the journal or the Indian Academy of Sciences. 
undergone will remain. It certainly can't be business-as-usual. The Covid19 crisis and its aftermath can either be seen as a longish temporary pause on the button of economic growth or it can be seen as an opportunity for reset, recalibration and rethink. Personally speaking, I believe in the latter, and therefore, this evening I want to address the issue of the role of science and technology in this transformed world going beyond the subject of diagnostics, vaccines and therapeutics for Covid-19 which all of you are very familiar with. I will be focusing on just one aspect of this 'transformed world' where S\&T has to play an enhanced and far more purposive role.

But a few remarks on Covid-19 itself may not be out of place. Let me highlight two gaps that have become even more glaring that should shape the direction of future S\&T. This emerged from a meeting that the Standing Committee that I chair had with various scientific departments on preparedness for Covod-19 and future pandemics.

First, it is distressing that the pharmaceutical manufacturing base covering both active pharmaceutical and drug intermediates has shrunk to alarming levels and over the past two decades has shifted mostly to China and some other countries. One view is that imports of cheap active pharmaceutical ingredients have fueled our export success story and that the Chinese API is used largely for domestic consumption. This is, in my view, a wholly false distinction. Indian consumers deserve the best quality as we prescribe for export markets.

Second, almost all the components, that is the reagents, enzymes, antibodies and equipment, are imported and this is a matter of national security no less.

India's pharmaceutical industry is undoubtedly an export success story. In the year 2018/19, for instance, our pharma exports were close to $\$ 21$ billion. But a case could clearly be made for greater 'import substitution' both from an economic and strategic point of view.

Even since the pandemic hit, there has been talk of revamping the regulatory system to accelerate repurposing of approved drugs and clinical molecules as well as development of new vaccines and therapeutics in extreme emergencies like the one, we are still going through. But this has to be consistent with global standards of safety and hence has its own limits. However, the two earlier points I made are eminently doable and is not beyond the capability and capacity of our vast S\&T infrastructure.

\section{III}

Covid-19 is undoubtedly a public health catastrophe and certainly calls for enhanced investments in R\&D that impinges directly on public health. But more fundamentally, I believe that the Covid-19 pandemic reflects fundamental ecological disequilibrium. Evidence has accumulated that loss of biodiversity and ever-increasing human incursions into the natural world has contributed heavily to the outbreak and spread of epidemic diseases. Understanding the three Es - evolution, ecology and the environment - will be key to identifying potential pandemics. Covid-19 also reinforces the need to pay far greater attention to the bio-sciences - and I stress sciences - that underpin agriculture, health and the environment that are going to be profoundly impacted by the current pandemic.

There is also now robust scientific evidence to show, for instance, how air pollution exacerbates the impacts of Covid-19. Public health science and environmental science are two sides of the same coin. In fact, I have been saying for over a decade now that our environmental problems - like air pollution, water pollution, chemical contamination, deforestation, waste generation and accumulation, land degradation and excessive use of pesticides - all have profound public health consequences both in terms of morbidity and mortality and hence demand urgent actions. The traditional 'grow now, pay later' model is not only unsustainable in the medium to long term but is dangerous to public health in the short term.

We have vigorous environmental activism in our country. That is to be applauded and strengthened even though in recent years there have been attempts to stifle it. We have strong environmental laws which need to be enforced without fear or favor, even though in recent years there have been efforts to have them diluted. But where I ask myself is cutting-edge (or even blunt-edge for that matter) environmental science in our universe of S\&T? It is useful to remind ourselves that the Ministry of Environment first set up in November 1980 by Indira Gandhi with herself as Minister had three scientists at its helm as long as she lived: Professor M.G.K. Menon, Dr. S.Z. Qasim and Dr. T.N. Khoshoo. When I was Environment Minister, I can now reveal I tried to get Dr. K. Vijayaraghavan as the Secretary but it did not quite work out and he went on to take charge of the Department of Biotechnology. Just 
a couple of weeks back, I am glad to say that an Indira Gandhi Chair in Environmental Science has been endowed at the National Institute of Advanced Studies in Bengaluru. I had something to do with this initiative and the choice of the subject for the chair and its location were very deliberate for I believe that Bengaluru offers the best ecosystem to create a collaborative interdisciplinary network for looking at environmental issues from the perspective of science and also increasingly public health.

IV

We live in a world where climate change is a reality. No longer can we argue about uncertainties in the monsoon, the frequency of extreme events, the retreat of the Himalayan glaciers and the increase in mean sea levels. A very recent report of the Ministry of Earth Sciences called 'Assessment of Climate Change over the Indian Region' is an excellent and up-to-date analysis that deserves wider debate and discussion. It also points to the need for making our future S\&T strategy in different areas anchored in an understanding of the impacts of climate change caused by continued emissions of greenhouse gases. This scientific understanding is essential, for what may be a solution at one point of time to one problem may soon become a threat in a different context. Take the example of HFCs, or hydroflurocarbons, that were at one time seen as the panacea to fix the depletion of the ozone layer. The depletion of the ozone layer has been fixed more or less but HFCs are a potent threat from a climate change perspective since their global warming potential is a thousand times that of carbon dioxide.

One of the things I had got done as Environment Minister was to create an Indian Network on Climate Change Assessment (INCCA). This was meant to be a wholly Indian IPCC so to speak. Most of you will know that the IPCC is the Intergovernmental Panel on Climate Change. INCCA brought out some very valuable reports on the impact of climate change in key sectors of the economy and equally importantly on key ecologically sensitive regions of the country like the Western Ghats and the Himalayan ecosystem. Sadly, as it happens so very often in our country, INCCA lost its steam and importance after I left. Who houses INCCA is immaterial: what is important that such a network remains active and collaborates with similar networks elsewhere in the world. The report of the Ministry of Earth Sciences is an opportunity to revive INCCA and give it a new momentum. Perhaps the various scientific academies in the country can get together and create a research consortium for this purpose without waiting for some government department or ministry to take the lead.

But climate change is only one of the planetary boundaries that are of grave concern and demanding of continuing scientific attention. In the pre-Covid-19 world, the Stockholm Resilience Centre had identified eight others: stratospheric ozone depletion, biodiversity loss and extinctions, chemical pollution and the release of novel entities, ocean acidification, freshwater consumption and the global hydrological cycles, land system change, nitrogen and phosphorous flows to the biosphere and oceans, and atmospheric aerosol loading. They have to be seen as interconnected systems because, as I have mentioned earlier, you can stay within one boundary but at the cost of the other. And how these will be affected by Covid-19 and its aftermath remains to be seen. Moreover, planetary boundaries are one thing, local carrying capacities are quite another. Of course, it could well be argued that if local carrying capacities are exceeded-like, for instance, in the Western Ghats or in the Himalayan region - planetary boundaries themselves will be disturbed. My point is simply this: science has to have both a global and local content. The latter unfortunately very often takes a back seat.

V

In September 2018, the American state of California - the world's fifth largest economy in itself - was the first to commit itself to carbon neutrality. The aim was to achieve this by 2045. In December 2019, a few weeks before the world became aware of the Covid-19 catastrophe, the European Union followed California's example but with the year 2050 in mind. In September 2020 China stunned the world by declaring its goal of carbon neutrality by 2060. And just a few weeks back, Japan and South Korea have joined the club announcing their intention to do so by 2050 like the EU. India too has to begin thinking very seriously about its level of ambition in this regard especially since it will have public health consequences as well-what, in the language of climate change negotiations, are called 'co-benefits'. We cannot always hide behind the fact that our per capita emissions will 
continue to be low - that is obvious, given the continued increase in the denominator. At the Paris Climate Change Conference in December 2015, we committed to having 40\% of our electricity generating capacity from non-fossil fuel sources by the year 2030. I have no doubt that we will reach this level. But please remember this is capacity and not generation. Renewables add impressively to capacity but their contribution to supply is far less significant. Even so, this milestone is an important one.

However, carbon neutrality is something different. Definitions vary, but in simple terms, and I am deliberately not getting into complications introduced by instruments like offsets, it should mean that for a country carbon emissions are equal to absorptions in carbon sinks, of which forests are one. Both sides of the equation are important and have to be addressed simultaneously. At Paris in December 2015, we made a commitment on carbon sequestration through forests, but I have serious doubts about its credibility. To my mind this is a matter of over-riding priority. We will definitely become a 5-trillion-dollar economy in a few years. That is an arithmetical inevitability, give or take a few years. There is no need to lose sleep over it. Carbon neutrality, on the other hand, is a far bolder and worthwhile goal the attainment of which has to be consciously engineered. It will involve massive scientific invention and technological innovation especially when it comes to removing greenhouse gases from the atmosphere. But let me add one note of caution here based on our disappointing experience with nuclear energy: there is simply no magic or silver bullet waiting for human ingenuity to harness. Every solution being put forward these days, most recently that which is being referred to as geo-engineering, are riddled with all sorts of complications that are not easy to resolve. Of course, renewables are an integral part of the solutions we seek but they have to be seen as more than just devices: they open up avenues for re-architecturing systems as a whole as has happened, for instance, in the German electricity sector over the past decade and a half.

By now you would have got a sense of where I am coming from: that the post-Covid-19 world is an opportunity for us to switch gears and make a radical departure from the past to make economic growth ecologically sustainable. Much of the infrastructure we need for the future is still be put in place - one estimate widely quoted that something like $70 \%$ of the infrastructure required in India by the year 2050 is waiting to be established. But will we grasp it or go for quick fixes in the name of accelerating pure and simple GDP growth remains to be seen. GDP growth must, without doubt, revive and get back to a steady 7-8\% growth path. However, in this postCovid19 world, we should make every effort, fueled by science and technology, that the G in GDP is not Gross but Green. In fact, some years back, Professor Sir Partha Dasgupta, of Cambridge University and one of the world's greatest environmental economists, had prepared a fairly detailed framework for this. India can and should show to the world how the measurement of economic growth can take place while taking into account both ecological pluses and minuses.

A fuller understanding of the ecology-health interface and interaction that I have spoken about had called for renewed scientific endeavors even before Covid-19 struck. It has assumed even greater significance now. And that significance is not momentary. It is integral to our future and so in one way, Covid-19 could be seen as a wake-up call, albeit a very painful and costly one. By its very nature, this new scientific enterprise calls for intensive collaboration across disciplines, both within the country and internationally as well. The institutional framework to ensure that this takes place is vital.

\section{VI}

Let me end by recalling that the use of technology based on terrific scientific advances very often has larger social and even at times ethical dimensions that cannot be summarily dismissed as being 'anti-science'. As Minister I had to grapple with the issue of transgenic food crops. The Standing Committee that I chair is now examining a draft law relating to the use of DNA technology in the justice delivery system, and let me tell you it presents a set of very complex issues that go beyond just science. The award of this year's Nobel Prize in Chemistry for the development of what is popularly being called 'genetic scissors' has been hailed and rightly so. But at the same time, one of co-winners has herself spoken of the ethical and philosophical aspects of the breakthrough. This will have to be addressed by us too sooner rather than later. In this I believe scientific academies such as yours will have to play a more active role.

Thank you. 